Original Article

\title{
Detection of human papillomavirus by hybrid capture and real time PCR methods in patients with chronic cervicitis and cervical intraepithelial neoplasia
}

\author{
Elisha Khandker \\ Department of Microbiology, Ibrahim Medical College, Dhaka, Bangladesh
}

\begin{abstract}
Background and objectives: Cervical cancer due to Human papillomavirus (HPV) is one of the leading causes of morbidity and mortality in women. Testing of HPV can identify women who are at risk of cervical cancer. Nowadays, molecular methods like real time polymerase chain reaction (PCR) and hybrid capture technique are applied for detecting HPV in cervical specimens. The objective of the present study was to determine the rate of HPV infection in women with chronic cervicitis and cervical intraepithelial neoplasia (CIN) by a commercial real time polymerase chain reaction test kit and by a hybrid capture HPV DNA test.

Methods: Women aged between 20 to 55 years with chronic cervicitis and CIN were enrolled in the study after obtaining informed consent. Cervical specimen was collected by using cervical brush and stored in transport medium until used. HPV was detected by High Risk Screen Real-TM Quant 2x (Sacace, Biotechnologies SrI, Italy) real time PCR kit (HR RT-PCR) and by Hybrid Capture-2 High-Risk HPV DNA (Hc-2; Digene Corporation, USA) test.

Results: Total 72 women with chronic cervicitis and CIN of different grades were included in the study. Out of this, HPV infection detected by HR RT-PCR was 31 (43\%) and by Hc-2 was 14 (19.4\%). Both the tests were able to detect HPV infection in all the CIN 3 cases and in most of the CIN 2 cases. However, HR RT-PCR detected higher number of HPV in chronic cervicitis and CIN1 cases.

Conclusion: The study has shown that HR RT-PCR and Hc-2 tests are equally effective in detecting HPV infection in patients with CIN 2 and CIN 3 lesions. However, HR RT-PCR is more sensitive test for detecting HPV in chronic cervicitis and early CIN lesions and, therefore can be used in epidemiological study to detect presence of HPV in general population.
\end{abstract}

IMC J Med Sci 2016; 10(2): 45-48

\section{Introduction}

Human papillomavirus (HPV) infection has a global distribution and has been identified as the leading cause for cervical cancer [1]. In Bangladesh, each year an estimated thirteen thousand women are diagnosed with cervical cancer and about six thousand die from the disease [2]. HPV are classified as high risk and low risk HPV. The high risk (HR) types include
HPV-16, 18, 31, 33, 35, 39, 45, 51, 52, 56, 58, 59, 68, 73, and 82. Among these, HPV-16 and 18 are responsible for approximately $70 \%$ of all cervical cancer cases [3, 4]. The diagnosis and accurate treatment of HPV infection depends on detection of HPV in the cervical smear and its genotyping. Several studies have shown that cervical cancer has decreased after the advent and implementation of Papanicolaou (PAP) test screening program $[5,6]$. Recently, several

\section{Address for Correspondence:}

Dr. Elisha Khandker, Lecturer, Department of Microbiology, Ibrahim Medical College, 122 Kazi Nazrul Islam Avenue, Shahbag, Dhaka, Email: elishakhandk@ymail.com 
molecular methods have been applied to identify HPV infection in patients with dysplastic changes. The first high risk HPV test approved by the USA Food and Drug Administration (FDA) was the Hybrid Capture-2 assay (Hc-2) manufactured by Qiagen, USA (Digene Corporation, USA). The Hc-2 detects HPV by hybridization of genotype-specific RNA probes to denatured viral DNA. The test has been optimized to detect $1.0 \mathrm{pg} / \mathrm{ml}$ of HPV target DNA or 5000 copies in the sample [7]. Another molecular test which is also frequently used to detect HPV infection in cervical cytology is real time PCR. PCR is a powerful method to detect cervical HPV infection and is used in epidemiological studies. It has a low detection limit of 10-200 copies [8]. The test depends on the amplification of the target DNA and quantification. In view of the above, the present study was undertaken to determine the rate of HPV infection in patients with chronic cervicitis and different grades of cervical intraepithelial neoplasia (CIN) by HR RT-PCR and Hc-2 assays .

\section{Materials and Methods}

This study was approved by the Ethical Review Committee of the Diabetic Association of Bangladesh. Informed written consent was obtained from each participant.

Study population and place: This study was carried out at Bangladesh Institute of Research and Rehabilitation in Diabetes, Endocrine and Metabolic Disorder (BIRDEM) and at a private hospital of Dhaka city from July 2012 to June 2013. Seventy two women aged between 20 to 55 years, who were diagnosed as cases of chronic cervicitis, CIN or invasive cancer by Papanicolaou (Pap) smear and histopathology of colposcopy directed biopsy, were enrolled in the study.

Collection of samples for detection of HPV for both molecular methods: The cervical specimen for detection of HPV was collected with the sampling cervical brush, provided with the HR RT-PCR kit (Sacace, Biotechnologies Srl, Italy). At first, excess mucus from the cervical os and surrounding ectocervix was removed with a cotton swab. The sampling brush was then inserted into the cervical $o s$, until the largest bristle touched the ectocervix. The brush was rotated three full turns counterclockwise and removed and immediately placed in $0.3 \mathrm{ml}$ of transport medium provided with the PCR kit. The container was shaken vigorously for 15-20 seconds and then the sample was divided equally in two sterile tubes for $\mathrm{Hc}-2$ and $\mathrm{HR}$ RT-PCR assay. The samples were stored at $-80^{\circ} \mathrm{C}$ until the tests were performed.

Detection of HPV by real time PCR: HPV High Risk Real-TM Quant 2x commercial kit (Sacace, Biotechnologies SrI, Italy) was used for extraction and detection of DNA by real time PCR. Here DNA was extracted and the target region E2 and E1 was amplified according to the instruction of the manufacturer. By this method HPV types 16, $18,31,33,35,39,45,51,52,56,58$, and 59 could be identified. A $\mathrm{Ct}$ value $\leq 33$ or HPV DNA concentration of $>\log 3$ was considered as positive. The kit did not differentiate between the different genotypes. This kit allows detecting HPV DNA in $100 \%$ of the test with a sensitivity of not less than 100 copies/ml.

Detection of high risk HPV by hybrid capture test: The Hc-2 High-Risk HPV DNA Test (Digene Corporation, USA) kit was used to detect high-risk HPV types 16, 18, 31, 33, 35, $39,45,51,52,56,58,59$ and 68 , by nucleic acid hybridization with signal amplification and chemiluminescent detection. Specimen containing the target DNA hybridizes with a specific HPV RNA probe. The resultant RNA:DNA hybrids are captured onto the surface of a microplate well coated with antibodies specific for the RNA:DNA hybrids. Immobilized hybrids then reacted with alkaline phosphatase conjugated antibodies specific for the RNA:DNA hybrids, and are detected with a chemiluminescent substrate. The intensity of the light emitted denotes the presence or absence of target DNA in the specimen. A measurement of relative light units (RLU) less than the cut off value $(<1)$ indicates the absence of the specific high-risk HPV DNA sequences tested or HPV DNA levels below the detection limit of the assay. Cut off RLU value of $\geq 1$ indicates presence of high risk HPV DNA. HC-2 high risk HPV DNA test detects as low as $1 \mathrm{pg} / \mathrm{ml}$ of target DNA which is equivalent to 5,000 HPV copies per assay. 


\section{Results}

Total 72 women with chronic cervicitis and different grades of CIN were included in the study. Out of 72 cases, $44(61.1 \%)$ and $28(38.9 \%)$ had chronic cervicitis and CIN, respectively (Table-1). The overall detection rate of high risk HPV among study population by HR RT-PCR and Hc-2 assays were $43.1 \%$ and $19.4 \%$, respectively. Table-1 shows that, among the chronic cervicitis cases, HPV positive rate was $20.5 \%$ by HR RT-PCR compared to $2.3 \%$ by Hc-2 assay. Out of total 28 CIN cases, $78.6 \%$ and $46.4 \%$ were positive for high risk HPV by HR RT-PCR and Hc-2 tests respectively. The rate of detection of HPV was significantly higher by HR RT-PCR than that of Hc-2 test in both chronic cervicitis and CIN 1 cases.

Table-1: The distribution of chronic cervicitis and CIN cases and rate of detection of HPV by HR RTPCR and Hc-2 methods

\begin{tabular}{lccc}
\hline \multirow{2}{*}{ Case } & No of & \multicolumn{2}{c}{ HPV positive by } \\
\cline { 3 - 4 } & cases & HRRT-PCR & Hc-2 \\
& $(\%)$ & n (\%) & n (\%) \\
\hline Chronic & 44 & 9 & 1 \\
cervicitis & $(61.1)$ & $(20.5)$ & $(2.3)$ \\
All CIN & 28 & 22 & 13 \\
$(1,2,3)$ & $(38.9)$ & $(78.6)$ & $(46.4)$ \\
Total & 72 & 31 & 14 \\
& & $(43.1)$ & $(19.4)$ \\
\hline
\end{tabular}

Note: For chronic cervicitis: $Z=2.7, p<0.01$ compared between HR RT-PCR and Hc-2 methods.

For CIN: $Z=2.5, p<0.01$, compared between HR $R T$ PCR and Hc-2 methods

Table-2: Rate of detection of HPV infection by $H R$ RT-PCR and Hc-2 methods in cases with different grades of $C I N$

\begin{tabular}{cccc}
\hline \multirow{2}{*}{$\begin{array}{c}\text { CIN } \\
\text { grades }\end{array}$} & \multirow{2}{*}{$\begin{array}{c}\text { No of } \\
\text { cases }\end{array}$} & $\begin{array}{c}\text { HR RT-PCR } \\
\text { n (\%) }\end{array}$ & $\begin{array}{c}\text { Hc-2 } \\
\mathbf{n}(\%)\end{array}$ \\
\hline CIN 1 & 14 & $8(57.1)$ & $1(7.1)$ \\
CIN 2 & 11 & $11(100)$ & $9(81.8)$ \\
CIN 3 & 3 & $3(100)$ & $3(100)$ \\
\hline
\end{tabular}

Table-2 compares HPV detection rate in different grades of CIN by both methods. The rate of detection of HPV by HR RT-PCR in CIN 2 and CIN 3 cases was $100 \%$ while by $\mathrm{Hc}-2$ test it was $81.8 \%$ and $100 \%$ respectively. The detection rate of HPV in CIN 1 was significantly $(\mathrm{p}<0.05)$ lower by Hc-2 assay (7.1\%) compared to HR RT-PCR $(57.1 \%)$.

\section{Discussion}

It is essential to understand the limitations and benefits of different types of molecular methods for proper detection of HPV infection [9-12]. This is necessary to implement the proper intervention for the management of CIN patients and undertaking decision regarding vaccination against HPV. In this study, we compared the Hc-2 with that of HR RTPCR assays for the detection of HPV in cervical specimens collected from patients having chronic cervicitis and CIN. The present study has revealed that compared to Hc-2 test, HR RT-PCR is capable of detecting HPV infection in significantly higher number of cases with chronic cervicitis and CIN 1 lesions. In the present study, HPV was detected in 9 cases of cervicitis and in 8 CIN 1 cases by HR RT-PCR compared to only 1 in cervicitis and 1 in CIN 1 cases by Hc-2 test. On the other hand, the rate of detection of HPV by both tests was almost similar $(100 \%$ and 81 to $100 \%)$ in cases with CIN 2 and 3 lesions. The low positivity rate by Hc-2 test could be due to presence of low viral load in chronic cervicitis and CIN 1 lesions. The HR RT-PCR test used in the present study could able to detect HPV as low as 100 copies while the Hc-2 assay had been optimized to be positive at 5000 copies per assay [8]. Hc-2 assay had been optimized to this threshold level of viral DNA as lower threshold level may not to be associated with cervical diseases and is clinically irrelevant [13]. It seems that HR RT-PCR is an appropriate method to be used for epidemiological purpose and to determine the presence or absence of HPV in a given community. However, in chronic cervicitis and CIN 1 cases the detection of HPV by molecular test like HR RT-PCR should always be correlated with the clinical manifestations as most of these cases may not progress to advanced lesions or cervical cancer. 
The study has demonstrated that HR RT-PCR and Hc-2 tests are equally effective in detecting HPV infection in patients with CIN 2 and CIN 3 lesions and HR RT-PCR is a sensitive test for detecting HPV in chronic cervicitis and early CIN lesions.

\section{Acknowledgement}

I am grateful to Mr. Ian T Martin, Vice President, Molecular Diagnostic (Asia Pacific, Qiagen Company) for providing the Kit.

\section{References}

1. Clifford GM, Smith JS, Plummer M, Munoz $\mathrm{N}$, Franceschi S. Human papillomavirus types in invasive cervical cancer worldwide: a metaanalysis. Br J Cancer 2003; 88(1): 63-73.

2. Sankaranarayanan R, Bhatla N, Gravitt PE, Basu P, Esmy PO, Ashrafunnessa KS, Ariyaratne Y, Shah A, Nene BM. Human papillomavirus infection and cervical cancer prevention in India, Bangladesh, Sri Lanka, and Nepal. Vaccine 2008; 26: 1-16.

3. Munoz N, Bosh FX, de Sanjose S, Herrero R, Shah KV, Snijders PJF, Meijer CJLM. Epidemioogical classification of Human papillomavirus types associated with cervical cancer. N Engl J Med 2003; 348: 518-527.

4. Munoz N, Bosh FX, Castellsague X, de Sanjose S, Hammoudad D, Shah KV, Meijer CJLM . Against which human papillomavirus types shall we vaccinate and screen? The international perspective. Int J Cancer 2004; 111(2): 278-285.

5. Franco EL, Duarte- Franco E, Ferenczy A. Cervical cancer: epidemiology, prevention and the role of human papillomavirus infection. Can Med Assoc J 2001; 164(7): 1017-1025.

6. IARC working group on evaluation of cervical cancer screening programmes. Screening for squamous cervical cancer: duration of low risk after negative result of cervical cytologyand its implecation for screening policies. $\mathrm{Br} \mathrm{Med} \mathrm{J}$ 1986; 293(6548): 659-654.

7. Lorincz A, Anthony J. Advances in HPV detection by hybrid capture ${ }^{\circledast}$. Papillomavirus Rep 2001; 12(6): 145-154.

8. Coutlee F, Rouleau D, Ferenczy A, Franco E. The laboratory diagnosis of genital human papillomavirus infections. Can J Infect Dis Med Microbiol 2005; 16(2): 83-91.

9. Baleriola C, Millar D, Melki J, Coulston N, Altman P, Rismanto N, and Rawlinson W. Comparison of a novel HPV test with the hybrid capture 2 and a refernce PCR method shows high specificity and positive predictive value for 13 high risk-human papillomavirus infections. Clin Virol J 2008; 42(1): 22-26.

10. Castle PE, Porras C, Quint WJ, Rodriguez AC, schiffman M, Gravitt PE, Gonzalez P, Katki HA, Silva S, Freer E, Van Doorn LJ, Jimenez S, Herrero R, and Hildescheim A. Comparison of two PCR based human papillomavirus genotyping methods. J Clin Microbiol 2008; 46(10): 3437-3445.

11. Iftner $\mathrm{T}$, Germ $\mathrm{L}$, Swoyer $\mathrm{R}$, Kjaer SK, Breugelmans JG, Munk C, Stubenrauch F, Anonello J, Bryan JT, Taddeo FJ. Study comparing human papillomavirus (HPV) real time multiplex PCR and hybrid Capture2 INNO-LiPA v2 HPV genotyping PCR assays. J Clin Microbiol 2009; 47(7): 2106-2113.

12. Menzo S, Ciavattini A, Bagnarelli P, Marinelli K, Sisti S, Clementi M. Molecualr epidemiology and pathogenic potential of underdiagnosed huamn papillomavirus types. BMC Microbiol 2008; 8: 112.

13. Snijders Peter JF, van den Brule Adrian JC, Meijer Chris LJM. The clinical relevance of human papillomavirus testing: relationship between analytical and clinical sensitivity. $J$ Path 2003; 201: 1-6. 